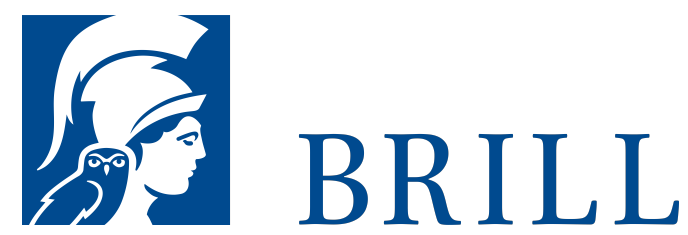

\title{
Das Problem der Wahrnehmung
}

\section{Author: Alexander Staudacher}

Das Problem der Wahrnehmung besteht darin, eine plausible Antwort auf eine scheinbar einfache Frage zu finden: 'Was sind die unmittelbaren Gegenstände der Wahrnehmung?' Die nahe liegende Commonsense-Antwort, dass es sich dabei um die physischen Gegenstände in der Umgebung des Betrachters handelt, wird durch eine Reihe von Argumenten in Frage gestellt, die vor allem auf den Umstand abheben, dass uns Dinge in der Wahrnehmung oft anders erscheinen als sie de facto beschaffen sind bzw. uns etwas in der Wahrnehmung erscheinen kann, obwohl gar kein entsprechender Gegenstand vorhanden ist. In der ersten Hälfte des 20 . Jahrhunderts wurden diese Argumente als Stütze für die so genannten Sinnesdatentheorien (z.B. von Russell und Moore) angesehen, die heute gemeinhin als äußerst unattraktiv gelten. Das Buch untersucht, wie unattraktiv solche Theorien tatsächlich sind, und welche Schwierigkeiten sich für deutlich populärere Alternativvorschläge wie die Adverbialtheorie, den so genannten Repräsentationalismus sowie relationale Theorien wie etwa die Theorie des Erscheinens ergeben.

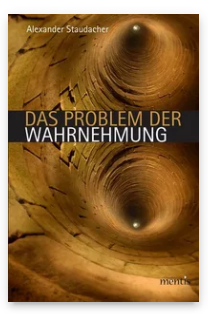

Pages: 373

Seiten

Language:

German

Subjects:

General,

Philosophy

Publisher: Brill | mentis

E-Book (PDF)

Released online:

o5 Oct 2011

ISBN: 978-3-

95743-927-7

List price

USD \$68.oo

Paperback

Publication date: o5 Oct 2011

ISBN: 978-3$89785-683-7$ List price USD \$68.oo 
For more information see brill.com

Order information: Order online at brill.com +44330 333 0049 | customerservices@brill.com Submission information: brill.com/authors

Titles published by Brill | Fink, Brill | mentis or Brill | Schöningh: +49(o)715413279216| brill@brocom.de 